\title{
Concept of an expandable cardiac valve for surgical implantation in infants and children
}

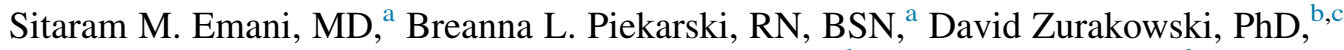 \\ Christopher A. Baird, MD, ${ }^{\mathrm{a}}$ Audrey C. Marshall, MD, ${ }^{\mathrm{d}}$ James E. Lock, MD, ${ }^{\mathrm{d}}$ and Pedro J. del Nido, MD ${ }^{\mathrm{a}}$
}

\begin{abstract}
Background: Options for cardiac valve replacement in children are limited to fixed-diameter prostheses that do not accommodate for somatic growth. An externally stented bovine jugular vein graft has been modified for surgical valve replacement in pediatric patients, with the intention of subsequent valve expansion in the catheterization laboratory as the child grows.

Methods: Pediatric patients at a single institution who underwent surgical implantation of an expandable bovine jugular vein valve between 2010 and 2014 were reviewed retrospectively. Forty-two patients underwent implantation at median age of 10 months (range, 3 weeks to 5.8 years) in aortic, mitral, pulmonary, or tricuspid positions. Numerous techniques for valve modification and implantation were used.
\end{abstract}

Results: The valve was competent with low gradient acutely postoperatively in all patients. Eight patients experienced central or paravalvular deterioration, and 7 required reoperation for valve-related adverse outcomes. Twenty patients underwent at least one previous valve repair or replacement. Twenty patients underwent 32 episodes of catheter-based balloon expansion of the valve, exhibiting a significant decrease in median gradient from $12 \mathrm{~mm} \mathrm{Hg}$ to $8 \mathrm{~mm} \mathrm{Hg}(P<.001)$ with no significant increase in grade of regurgitation. At 12 months after implantation, Kaplan-Meier analysis indicated that $88 \%$ would be expected to be free from reoperation ( $95 \%$ confidence interval, $78 \%-98 \%$ ). A total of 6 deaths occurred, 3 before discharge and 3 late.

Conclusions: A surgically implanted externally reinforced bovine jugular vein demonstrates acceptable short-term function and is amenable to catheter-based enlargement as the child grows. Modification of valve design and implantation techniques are necessary to reduce perivalvular complications. (J Thorac Cardiovasc Surg 2016;152:1514-23)

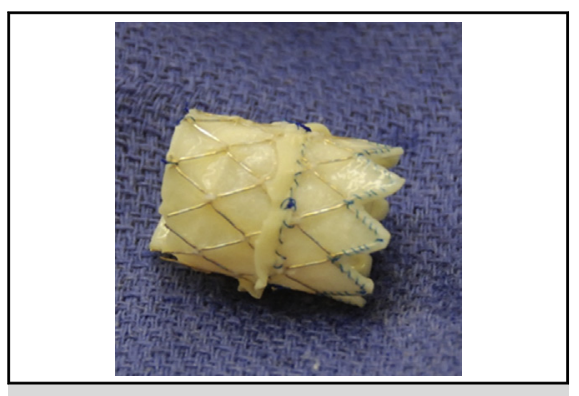

Modified Melody valve with pericardial skirt and shortened stent.

\section{Central Message}

This novel design for an expandable valve demonstrates acceptable function and is amenable to enlargement as the child grows.

\section{Perspective}

Options for cardiac valve replacement in children are limited to fixed-diameter prostheses that do not accommodate for somatic growth. An externally stented bovine jugular vein graft has been modified for surgical valve replacement in pediatric patients, and demonstrates the ability for subsequent valve expansion in the catheterization laboratory as the child grows.

See Editorial Commentary page 1524.
The prosthetic valves commonly used for semilunar or atrioventricular (AV) valve replacement in children function at a fixed diameter, and thus require reoperation for replacement as a child grows. For patients undergoing implantation of an allograft conduit in the right ventricular

From the Departments of ${ }^{\mathrm{a}}$ Cardiac Surgery, ${ }^{\mathrm{b}}$ Anesthesia, ${ }^{\mathrm{c}}$ Surgery, and ${ }^{\mathrm{d}}$ Cardiology, Boston Children's Hospital, Boston, Mass.

Read at the 96th Annual Meeting of The American Association for Thoracic Surgery, Baltimore, Maryland, May 14-18, 2016.

Received for publication March 1, 2016; revisions received July 19, 2016; accepted for publication Aug 19, 2016; available ahead of print Sept 28, 2016.

Address for reprints: Sitaram M. Emani, MD, Boston Children's Hospital, 300 Longwood Ave, Bader 273, Boston, MA 02115 (E-mail: Sitaram.Emani@cardio. chboston.org).

$0022-5223 / \$ 36.00$

Copyright (๑) 2016 by The American Association for Thoracic Surgery

http://dx.doi.org/10.1016/j.jtcvs.2016.08.040 outflow tract (RVOT) position, catheter-based expansion of the valve allows for delays in surgical reoperation, but is frequently associated with the development of valvular insufficiency. ${ }^{1}$ Whereas placement of an oversized valve at the time of original surgical replacement in anticipation of somatic growth may shorten the time to reoperation, this is not always feasible owing to space limitations. ${ }^{2}$

A bioprosthetic valve with an adjustable diameter that can be subsequently expanded with somatic growth is an

Scanning this $\mathrm{QR}$ code will take you to a video for the article. To view the AATS 2016 Webcast, see the URL next to the video thumbnail. 


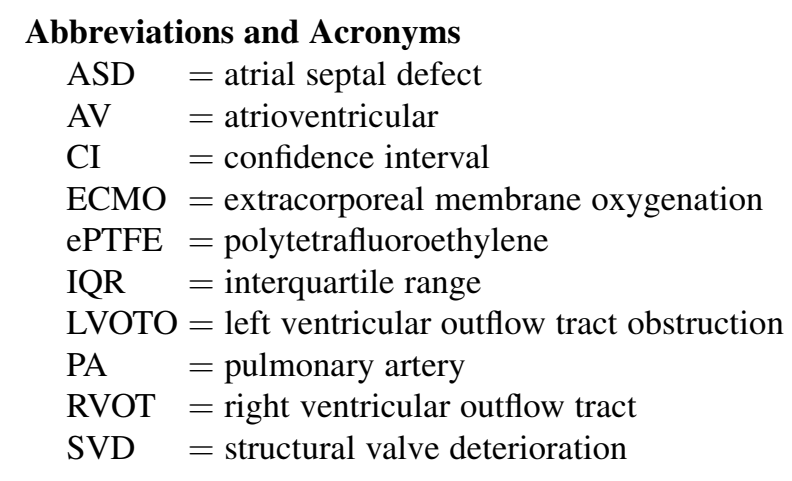

attractive alternative for surgical valve replacement in children. A valved bovine jugular vein mounted within a platinum-iridium stent (Melody valve; Medtronic, Minneapolis, Minn), approved for transcatheter implantation into the RVOT, has demonstrated acute valvular competence within a size range of 10 to $22 \mathrm{~mm} .{ }^{3,4}$ The Melody valve can be modified for surgical implantation into semilunar or $\mathrm{AV}$ valve positions. We hypothesize that surgical valve replacement with the bovine jugular vein valve at a compressed diameter is associated with acceptable short-term valve performance, and that subsequent catheter-based valve expansion after somatic growth is feasible with durable valvular function.

\section{METHODS}

All patients at Boston Children's Hospital who underwent surgical implantation of the Melody valve at a compressed diameter $(<18 \mathrm{~mm})$ with the intent of subsequent catheter-based expansion between May 2010 and November 2014 were identified, and a retrospective review of medical records was performed after approval by the Boston Children's Hospital Institutional Review Board. Insertion of the Melody valve in the mitral, tricuspid, and aortic positions was done under off-label use designation. Candidates for surgical Melody insertion typically included infants and young children deemed too small for implantation of a traditional mechanical or bioprosthetic valve (annulus size $<16 \mathrm{~mm}$ ). For patients requiring RVOT reconstruction, surgical Melody implantation served as an alternative to implantation of a homograft or xenograft valve for patients in whom long-term valve competence was deemed essential (eg, those at risk for pulmonary hypertension and right ventricular dysfunction).

\section{Operative Procedure}

Although the surgical technique differed according to position of implantation, the guiding principle was similar-implantation that would enable subsequent transcatheter balloon expansion as the child grows. To accomplish this goal, methods of fixation were designed to allow subsequent transcatheter expansion in a controlled fashion. Procedural details, including valve modification and insertion techniques, were obtained from operative reports, and complications related to surgical implantation were recorded.

For AV valve replacement, the technique for implantation has been described previously (Video 1$)^{3-5}$ The valve preparation and implantation technique was similar for the aortic position. A circumferential skirt of bovine pericardium was sewn externally to the stent at its midsection to facilitate fixation to the valve annulus. For selected patients who underwent stent and graft wall resection, the

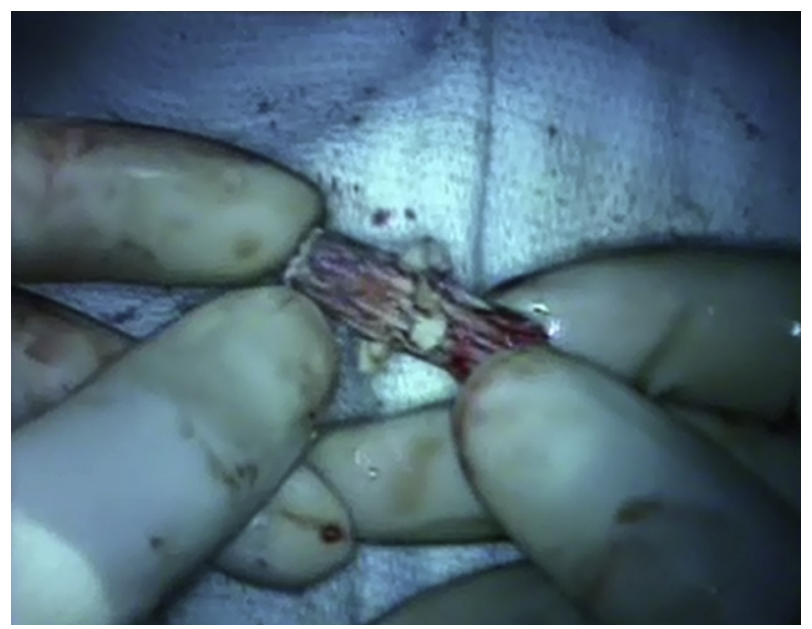

VIDEO 1. Insertion of the Melody valve into the mitral position with a subsequent saline test and balloon dilation. Video available at http:// www.jtcvsonline.org/article/S0022-5223(16)31072-8/addons.

skirt was attached to the stent below the level of the graft resection. The circumferential skirt was sutured to the annulus with either interrupted or continuous sutures.

The device was oriented to maintain alignment of resected graft segments with coronary ostia before suture implantation. After annular fixation, balloon dilation of the valve was performed. The balloon size was $1 \mathrm{~mm}$ greater than the AP mitral annular measurement obtained by preoperative transthoracic or transesophageal echocardiography, as confirmed intraoperatively by ensuring passage of a similar-sized Hegar dilator through the annulus.

Implantation into the pulmonary position was performed by orthotopic replacement of the main pulmonary artery (PA) as a conduit, implantation within a polytetrafluoroethylene (ePTFE) tube graft, or implantation within a native PA after longitudinal pulmonary arteriotomy. To facilitate a distal anastomosis of the conduit to the branch PA, the valve was modified by suture addition of a sleeve of ePTFE or bovine pericardium to the distal end of the stent. Once the distal anastomosis was complete, the proximal anastomosis to the right ventriculotomy site was performed by direct suture of the stent to the RV muscle posteriorly, and the addition of an ePTFE or bovine pericardial hood anteriorly. Before completion of the proximal hood, the valve was expanded to the appropriate size. For the RVOT position, the balloon diameter was selected as $z=0$.

Postoperative management included aspirin for antiplatelet therapy indefinitely. Testing with Verify Now was performed to ensure adequate dosing and therapeutic effect. Echocardiography was performed before discharge and at routine 2- to 4-month intervals to evaluate the progression of transvalvular gradient and regurgitation.

\section{Catheter-Based Valve Expansion}

A patient was deemed a candidate for re-expansion if the gradient across the prosthesis as measured by pulse wave Doppler increased with somatic growth. Although no predefined threshold values for gradient triggered reintervention, a precipitously rising gradient and absolute value $>10 \mathrm{~mm}$ $\mathrm{Hg}$ for a mitral or tricuspid valve and $40 \mathrm{~mm} \mathrm{Hg}$ for an RVOT or aortic valve position were considered indications.

At catheterization, femoral venous access was used to approach the valve. For mitral dilation, the left atrium was accessed through either a previously placed atrial septal defect (ASD) or transseptal puncture. The balloon size used for expansion was recorded and compared with the original balloon size used at implantation. Gradient across the prosthesis and regurgitation grade were recorded immediately before and after catheterbased expansion. 
Data collected from clinical follow-up included gradient and degree of valvular regurgitation immediately after implantation, at hospital discharge, and at most recent follow-up. Structural valve deterioration (SVD) was classified as "central regurgitation" (regurgitation resulting from malcoaptation of leaflets) or as "noncentral deterioration" (including paravalvular regurgitation or stent fractures). Progressive development of transvalvular stenosis was not included within definition of SVD as increasing gradient with somatic growth was anticipated and prompted transcatheter valve expansion. For patients who underwent catheterbased expansion of the Melody valve, the time to first cardiac catheterization, interval between dilations, and total number of interventions for valve expansion were documented.

\section{Statistical Analysis}

In the full cohort of patients who underwent surgical Melody valve implantation, freedom from mortality or transplantation, freedom from SVD, and freedom from nontransplantation reoperation were analyzed using the Kaplan-Meier product-limit method to account for censoring with $95 \%$ confidence intervals (CIs) along the curves determined using Greenwood's formula. The median postoperative gradient and amount of regurgitation before and after balloon dilation were compared by the nonparametric Wilcoxon signed-rank test. Melody valve sizes at implantation and most recent follow-up were compared using the paired $t$ test. Statistical analysis was performed using SPSS version 22.0 (IBM, Armonk, NY). A 2-tailed $P$ value $<.05$ was considered statistically significant. Based on the projected censoring at 12 months postimplantation, the sample size of 42 patients provided $80 \%$ power for estimating freedom from SVD as well as reoperation to within an $8 \%$ margin according the $95 \% \mathrm{CI}$ interval using the KaplanMeier method. In addition, the sample size provided $80 \%$ power for detecting a $50 \%$ relative change in median transvalvular gradient after balloon dilation (nQuery Advisor version 7.0; Statistical Solutions, Cork, Ireland).

\section{RESULTS}

Forty-two patients underwent surgical implantation of an expandable bovine jugular vein valve into RVOT $(n=15)$, mitral $(n=24)$, aortic $(n=1)$, or tricuspid $(n=3)$ positions. The median follow-up was 377 days for the entire cohort. Patient characteristics are outlined in Table 1. Median age at implantation was 10 months (range, 3 weeks to 5.8 years). Indications for valve replacement included valvular regurgitation (moderate or greater) in 18 (mitral, $\mathrm{n}=10$; RVOT, $\mathrm{n}=5$; tricuspid, $\mathrm{n}=2$; aortic, $\mathrm{n}=1$ ), valvular stenosis (moderate or greater) in 12 (mitral, $\mathrm{n}=9$; RVOT, $\mathrm{n}=3$ ), and both regurgitation and stenosis in 7 (mitral, $\mathrm{n}=5$; RVOT, $\mathrm{n}=2$ ). A median of 1 (range, 1-3) previous operative procedures for valvular repair or replacement had been performed before Melody valve implantation.

Procedural details, including valve modification and insertion techniques, are outlined in Table 2. The initial median size of expansion of the valve for all 42 patients was $14 \mathrm{~mm}$ (range, 10-22 mm). Additional procedures at the time of implantation included PA reconstruction $(n=26)$, fenestrated ASD closure $(n=12)$, valvuloplasty $(n=10)$, ventricular septal defect closure $(n=8)$, takedown of a Blalock-Taussig shunt $(\mathrm{n}=3)$, obstruction resection $(n=4)$, the Glenn procedure $(n=2)$, AV canal repair $(n=2)$, coarctation repair $(n=2)$, patent foramen ovale closure $(\mathrm{n}=1)$, endocardial fibroelastosis resection
TABLE 1. Demographic data for the expandable valve cohort $(n=42)$

\begin{tabular}{lc}
\hline \multicolumn{1}{c}{ Characteristic } & Value \\
\hline Age, mo, median (IQR) & $10(6-28)$ \\
Sex, $\mathrm{n}(\%)$ & \\
$\quad$ Male & $29(69)$ \\
Female & $13(31)$ \\
Weight, kg, mean $\pm \mathrm{SD}$ & $8.5 \pm 4.0$ \\
Body surface area, ${ }^{2}$, mean $\pm \mathrm{SD}$ & $0.42 \pm 0.14$ \\
Diagnosis, $\mathrm{n}(\%)$ & \\
Tetralogy of Fallot & $10(24)$ \\
Hypoplastic left heart/Shone's complex & $16(38)$ \\
Atrioventricular canal defect & $8(19)$ \\
Pulmonary atresia with intact ventricular & $3(7)$ \\
$\quad$ septum & \\
$\quad$ Hypoplastic left heart syndrome & $3(7)$ \\
Pulmonary stenosis/atresia & $2(5)$ \\
Prematurity, $\mathrm{n}(\%)$ & $5(12)$ \\
Previous cardiac surgery, $\mathrm{n}(\%)$ & $35(83)$ \\
Previous valve repair or replacement, $\mathrm{n}(\%)$ & $25(60)$ \\
Size of intraoperative valve expansion, mm, & $14(12-16) ;$ range, $10-22$ \\
$\quad$ median (IQR) & \\
Intensive care unit stay, d, median (IQR) & $6(4-14)$ \\
Length of hospital stay, d, median (IQR) & $11(7-23)$ \\
\hline$I O R$, Interquartile range; $S D$, standard deviation. &
\end{tabular}

$(\mathrm{n}=2)$, and the Rastelli procedure $(\mathrm{n}=1)$. Intraoperative echocardiography after implantation was used to evaluate valvular function. Valvular gradient and regurgitation according to implantation position are specified in Table 2. In the 42 patients, the median gradient of the Melody valve at this time point was $2 \mathrm{~mm} \mathrm{Hg}$ (interquartile range [IQR], 0-4 $\mathrm{mm} \mathrm{Hg}$; full range, $0-50 \mathrm{~mm} \mathrm{Hg}$ ), and regurgitation was mild or less in 39 patients.

The Kaplan-Meier estimated freedom from mortality or transplantation was $83 \%$ at 12 months and $77 \%$ at 24 months (Figure 1, A). Six deaths occurred (3 inhospital deaths, 3 late), including 4 in patients who underwent mitral valve replacement and 2 in those who underwent tricuspid valve replacement. Three of the 6 deaths occurred in patients receiving extracorporeal membrane oxygenation (ECMO) preoperatively owing to severe ventricular dysfunction, AV valve regurgitation, and multisystem organ failure. AV valve replacement was performed in an attempt to separate these patients from ECMO. In these 3 patients, prosthetic valve function was considered adequate, albeit difficult to assess owing to ongoing mechanical circulatory support (ECMO or ventricular assist device). Of the 3 late deaths, 1 death was presumably due to arrhythmia, and 2 patients with hypoplastic left heart complex died as a result of severe ventricular noncompliance and pulmonary hypertension. In all 3 patients, valvular competence and a gradient $<5 \mathrm{~mm} \mathrm{Hg}$ were demonstrated by cardiac catheterization and echocardiography.

One patient underwent cardiac transplantation at 3 months after mitral valve replacement. In this neonate 
TABLE 2. Operative techniques for surgical implantation of the Melody valve with postoperative gradients and long-term outcomes

\begin{tabular}{|c|c|c|c|c|}
\hline & $\begin{array}{c}\text { Mitral } \\
(n=24)\end{array}$ & $\begin{array}{c}\text { RVOT } \\
(n=14)\end{array}$ & $\begin{array}{c}\text { Tricuspid } \\
(\mathbf{n}=\mathbf{3})\end{array}$ & $\begin{array}{l}\text { Aortic } \\
(\mathbf{n}=\mathbf{1})\end{array}$ \\
\hline Melody stent trimmed, distal, $\mathrm{n}(\%)$ & $9(38)$ & $8(57)$ & 0 & $1(100)$ \\
\hline Melody stent trimmed, proximal, $\mathrm{n}(\%)$ & $16(66)$ & $7(50)$ & $2(67)$ & 0 \\
\hline Addition of pericardial skirt, n (\%) & $18(75)$ & $1(7)$ & $1(33)$ & $1(100)$ \\
\hline Sutured directly to native tissue, $\mathrm{n}(\%)$ & $24(100)$ & $9(64)$ & $3(100)$ & $1(100)$ \\
\hline Melody placed within ePTFE tube graft, n (\%) & 0 & $1(7)$ & 0 & 0 \\
\hline Sutured with pericardial hood/cuff, n (\%) & 0 & $8(57)$ & 0 & 0 \\
\hline Postoperative gradient, $\mathrm{mm} \mathrm{Hg}$, median (range) & $3(0-12)$ & $0(0-50)$ & $2(0-10)$ & 0 \\
\hline Postoperative grade, median (range) & None (none-moderate) & None (none-severe) & Mild (none-mild) & Mild \\
\hline Death, n $(\%)$ & $4(17)$ & 0 & $2(67)$ & 0 \\
\hline Cardiac transplantation, $\mathrm{n}(\%)$ & $1(4)$ & 0 & 0 & 0 \\
\hline Central SVD, n (\%) & $1(4)$ & $2(14)$ & 0 & 0 \\
\hline Noncentral deterioration, $\mathrm{n}(\%)$ & $3(13)$ & $2(14)$ & 0 & 0 \\
\hline
\end{tabular}

RVOT, Right ventricular outflow tract; $e P T F E$, polytetrafluoroethylene; $S V D$, structural valve deterioration.

with severe ventricular dysfunction and flail anterior mitral leaflet, transplantation was the intended long-term therapy, and valve replacement was performed as a bridge to planned transplantation.

Performance of the bovine jugular vein valve was assessed based on freedom from SVD (ie, moderate or greater regurgitation on echocardiography or development of stent fracture). Three patients $(7.1 \%)$ developed central valve regurgitation, and 5 patients $(11.9 \%)$ developed noncentral deterioration (perivalvular leaks or stent fracture). Of the 3 patients who developed central SVD, 1 underwent replacement in the mitral position and 2 underwent replacement in the RVOT position. Of the 5 patients who developed noncentral deterioration, 3 did so after mitral replacement and the other 2 did so after RVOT reconstruction. The Kaplan-Meier curve in Figure 1, $B$ shows the number of
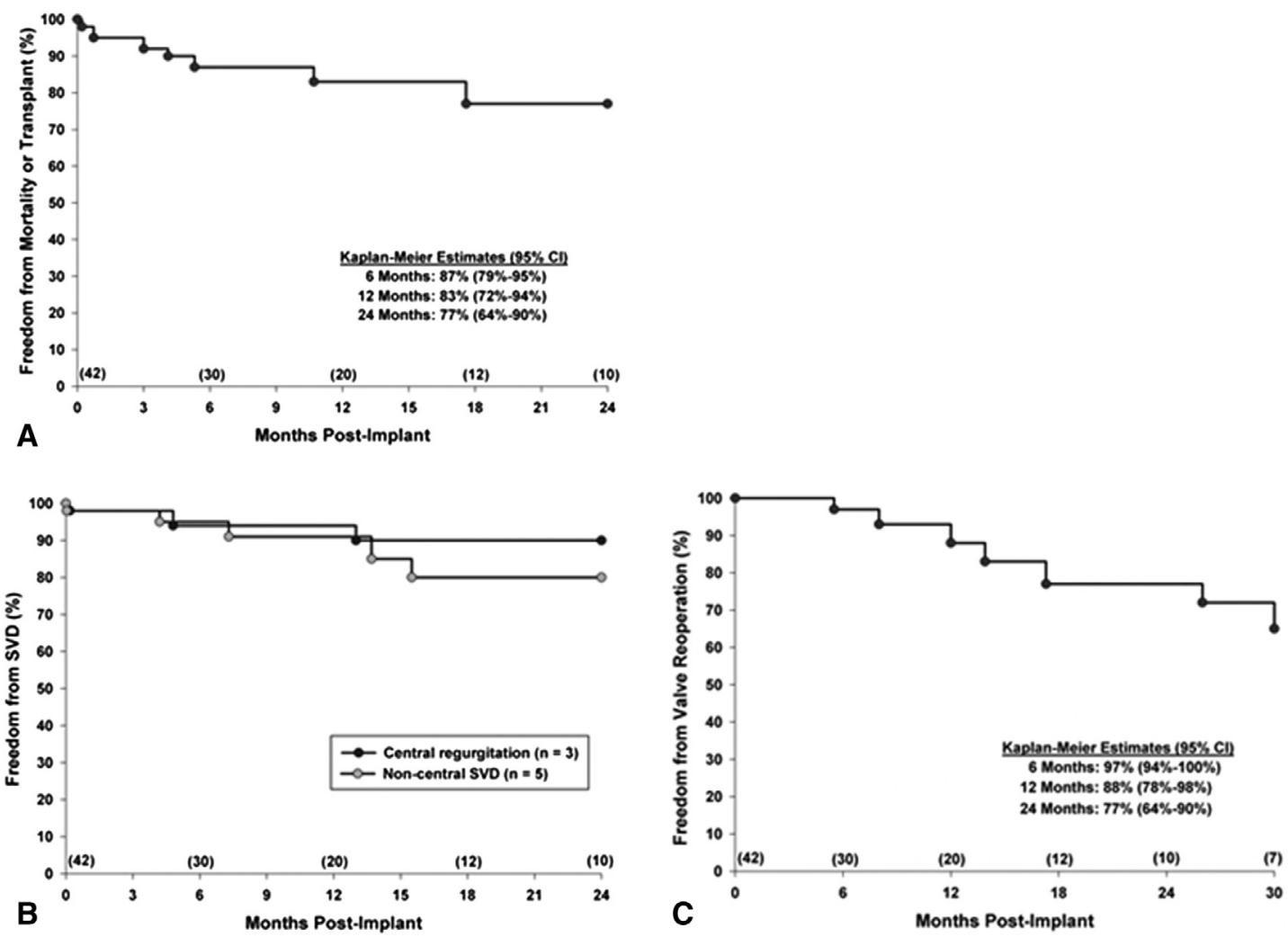

FIGURE 1. Kaplan-Meier curves depicting freedom from mortality or cardiac transplantation (A), structural valve deterioration (SVD) (B), and cardiac reoperation (C). SVD is categorized as central regurgitation and noncentral deterioration. $C I$, Confidence interval. 

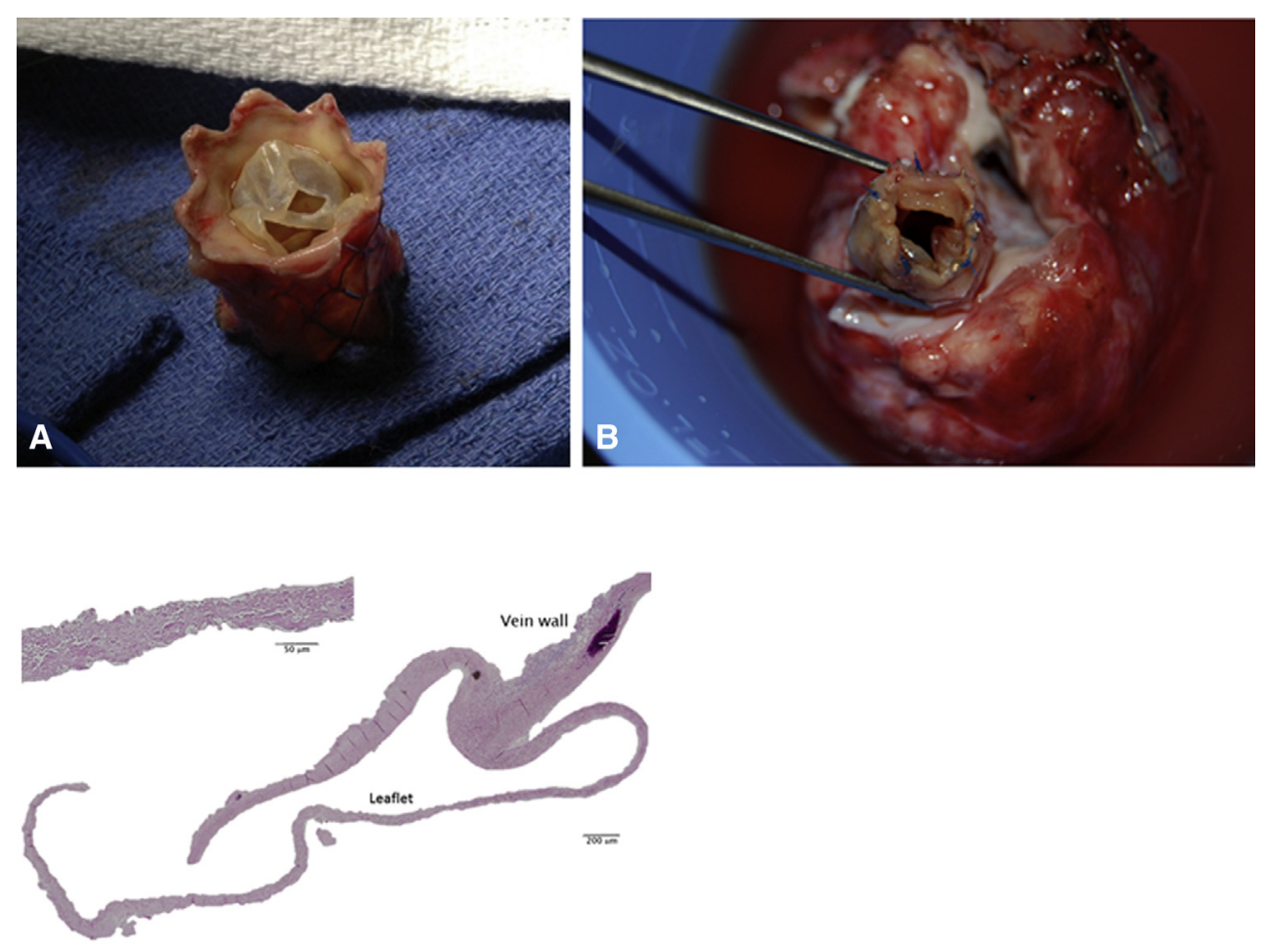

C

FIGURE 2. Gross examination of explanted valve from a patient at 3 months after implantation with suture injury to leaflet (A), and patient undergoing planned cardiac transplantation (B) demonstrating thin and mobile leaflets. Shown is a low-power $(4 \times)$ view of an hematoxylin and eosin-stained section through an explanted Melody valve leaflet and attached section of jugular vein wall at 12 months after implantation. $\mathrm{C}$, The leaflet is thin, as seen in the $20 \times$ magnification (inset). No inflammation or calcification of the leaflet is evident, whereas areas of calcification and inflammation are present in the vein wall.

months postimplantation that these patients are expected to be free from central valve regurgitation.

Of the 3 patients who developed central regurgitation, 1 patient did so within 1 week of implantation in the RVOT position. In this patient, excessive resection of the distal stent resulted in injury to the valve apparatus. A second patient with pulmonary atresia and a hypoplastic right ventricle underwent valve placement in the RVOT position with a concomitant bidirectional Glenn procedure as part of a right ventricular rehabilitation strategy. In the setting of minimal flow across the right ventricle, this patient developed severe regurgitation at 12 months postoperatively. In both of these patients, conduit re-replacement was not performed. A third patient underwent placement in the mitral position, but at 5 months central regurgitation of unclear etiology was discovered. At explantation, a perforation in one of the leaflets was found (Figure 2, $A$ ), and injury related to suture placement at the time of implantation was suspected.

Noncentral valve deterioration was detected in 5 patients. The Kaplan-Meier curve in Figure 1, $B$ shows the number of months postimplantation that these patients are expected to be free from noncentral deterioration. In 2 of these patients, the valve was implanted within a circumferential tube, either a native RVOT or an ePTFE tube graft, without circumferential proximal and distal anastomoses. In both of these patients, a significant perivalvular leak developed soon after the procedure, necessitating reoperation for re-replacement with a traditional fixed-diameter bioprosthetic valve. The remaining 3 patients underwent valve implantation into the mitral position. In 2 of these patients, significant perivalvular regurgitation developed, and dehiscence of the bovine pericardial skirt from the stent apparatus was discovered at reoperation or autopsy. In the third patient, stent fractures were detected by catheterization approximately 18 months after implantation. Extensive resection of the valve stent and graft (proximal, distal, and sinus facing the left ventricular outflow tract), performed at the time of implantation to avoid left ventricular outflow tract obstruction (LVOTO), contributed to valve instability. Even though valvular function was deemed adequate (4 $\mathrm{mm} \mathrm{Hg}$ gradient and trivial regurgitation), valve re-replacement was performed. Extraction of the valve in the patients who experienced valve deterioration was uncomplicated, with no evidence of erosion into adjacent structures. 

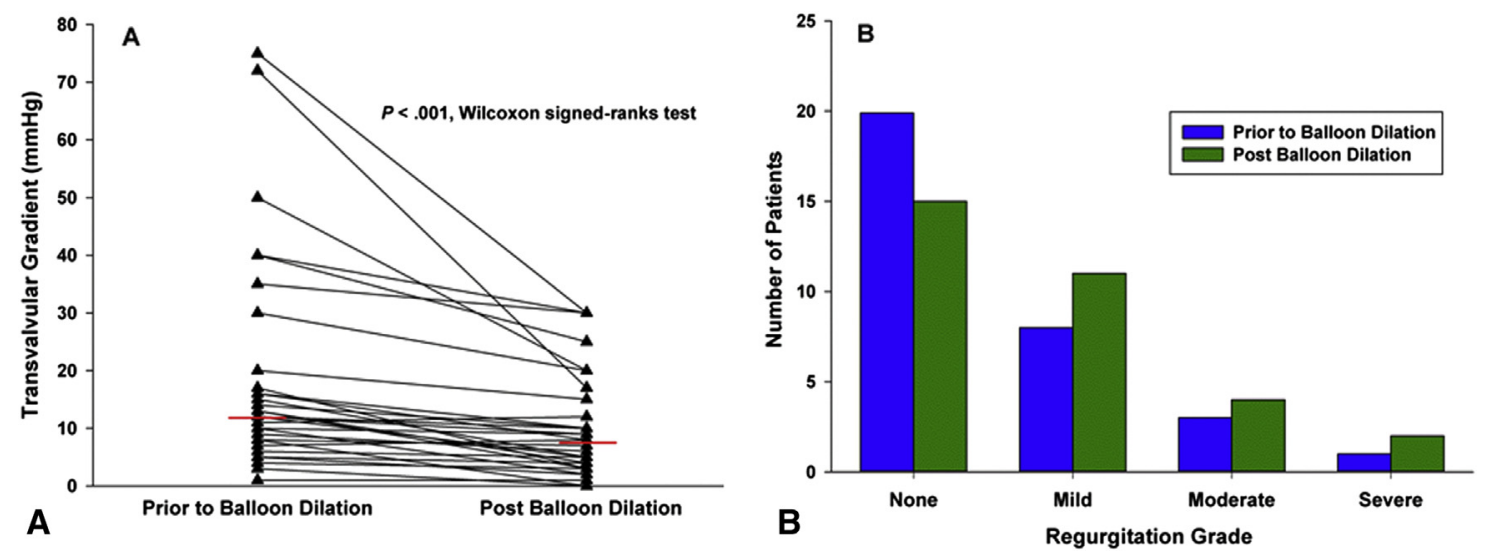

FIGURE 3. Transvalvular gradient (A) and regurgitation grade (B) immediately before and after balloon dilation of the valve. A significant reduction in transvalvular gradient is seen $(P<.001)$. The grade of regurgitation was not significantly different before and immediately after balloon dilation.

Nontransplantation cardiac reoperation was performed in 7 patients, including 6 patients who underwent valve rereplacement and 1 patient who underwent reoperation for relief of LVOTO that developed approximately 2.5 years after valve implantation. Tilting of the distal portion of the valve into the left ventricular outflow tract contributed to LVOTO in this patient, and resulted in several catheterbased interventions followed by reoperation. KaplanMeier analysis indicates that $88 \%$ (95\% CI, 78\%-98\%) are expected to be free from reoperation at 12 months after implantation (Figure 1, C).

Leaflet morphology and histology examined in 3 patients undergoing valve excision at 3,9 , and 12 months after implantation demonstrated thin and relatively acellular tissue without evidence of calcification or inflammation. Representative gross imaging and histology are shown in Figure 2.

In a subgroup of 20 patients who underwent balloon dilation for expansion of the Melody valve, the median time to first dilation was 6 months after implantation (range, 1 week to 35 months). Nine patients underwent a second balloon dilation at a median of 6 months after the first balloon dilation (range, 1 week to 41 months). Three patients underwent a third balloon dilation at a median of 11 months after the second dilation (range, 4-37 months).

An analysis of 32 episodes of balloon dilation in the 20 patients revealed a significant decrease in median transvalvular gradient from $12 \mathrm{~mm} \mathrm{Hg}$ (IQR, 8-20 mm Hg) immediately before balloon dilation to $8 \mathrm{~mm} \mathrm{Hg}$ (IQR, 3-14 $\mathrm{mm} \mathrm{Hg}$ ) immediately after dilation (Figure 3 ). The median grade of valvular regurgitation was not significantly different before balloon dilation and immediately after dilation (Table 3). One patient developed moderate regurgitation immediately after dilation that subsequently decreased to mild. The median gradient of the Melody valve on the most recent follow-up echocardiogram was $7 \mathrm{~mm} \mathrm{Hg}$ (IQR, 1-15 mm $\mathrm{Hg}$; full range, $0-48 \mathrm{~mm} \mathrm{Hg}$ ). The median size of the Melody valve in this subgroup increased significantly, from $14 \mathrm{~mm}$ (range, 10-18 mm) at implantation to $16 \mathrm{~mm}$ at the most recent dilation (full range, $10-21 \mathrm{~mm} ; P<.01$ ).

\section{DISCUSSION}

This report describes the application of an expandable cardiac valve in pediatric patients undergoing valve replacement. The Melody valve has shown acceptable short-term durability. Importantly, we have demonstrated the feasibility of balloon expansion of this valve with preserved valvular function up to several years after initial implantation. Nonetheless, further refinements in design and implantation technique are needed to reduce the complications related to SVD. Patients undergoing AV valve replacement are at high risk of mortality despite acceptable prosthetic valve function.

There are several features that make the stented bovine jugular vein graft optimal for expandable valve design. The ratio of commissural height to valve diameter is higher than that in systemic semilunar valves, which allows coaptation to occur over a range of diameters within a physiological range. The thin support structure maximizes the internal to external orifice area, permitting compression of a 22-mm-diameter valve to $10 \mathrm{~mm}$ diameter without compromising the internal orifice area.

Long-term pliability of the leaflets is critical to the valve's ability to maintain competence after balloon expansion at a subsequent time point. In this study, gross and histological assessment of explanted valves demonstrated thin, pliable leaflets without calcification or inflammation, even several years after implantation. When implanted in the AV valve or aortic positions, the Melody valve is secured to the annulus at its midsection by a pericardial skirt. The circumferential graft wall shields the internal leaflets from encroachment by pannus tissue, which impairs leaflet mobility after traditional prosthetic replacement. 
TABLE 3. Transvalvular gradient and regurgitation immediately before and after balloon dilation

\begin{tabular}{|c|c|c|c|}
\hline Catheter reintervention & $\begin{array}{c}\text { Before } \\
\text { balloon } \\
\text { dilation }\end{array}$ & $\begin{array}{c}\text { After } \\
\text { balloon } \\
\text { dilation }\end{array}$ & $P$ value \\
\hline \multicolumn{4}{|l|}{ Balloon dilation \#1 } \\
\hline \multicolumn{4}{|l|}{ Mitral position $(n=12)$} \\
\hline \multicolumn{4}{|l|}{ Gradient, mm Hg } \\
\hline Median (IQR) & $12(8-13)$ & $6(3-10)$ & $.006^{*}$ \\
\hline Range & 4-17 & $0-12$ & \\
\hline \multicolumn{4}{|l|}{ Regurgitation grade } \\
\hline Median (IQR) & $1(0-1)$ & $0(0-1)$ & .18 \\
\hline Range & $0-3$ & $0-3$ & \\
\hline \multicolumn{4}{|l|}{ RVOT position $(\mathrm{n}=7)$} \\
\hline \multicolumn{4}{|l|}{ Gradient, mm Hg } \\
\hline Median (IQR) & $40(30-72)$ & $20(17-30)$ & $.027 *$ \\
\hline Range & $0-75$ & $0-30$ & \\
\hline \multicolumn{4}{|l|}{ Regurgitation grade } \\
\hline Median (IQR) & $1(0-1)$ & $0(0-2)$ & .18 \\
\hline Range & $0-3$ & $0-2$ & \\
\hline \multicolumn{4}{|c|}{ Tricuspid position $(\mathrm{n}=1)$} \\
\hline Gradient, mm Hg & 5 & 2 & \\
\hline Regurgitation grade & 0 & 0 & \\
\hline \multicolumn{4}{|l|}{ Balloon dilation \#2 } \\
\hline \multicolumn{4}{|l|}{ Mitral position $(\mathrm{n}=7)$} \\
\hline \multicolumn{4}{|l|}{ Gradient, mm Hg } \\
\hline Median (IQR) & $10(5-15)$ & $5(4-9)$ & $.017 *$ \\
\hline Range & 3-16 & $0-10$ & \\
\hline \multicolumn{4}{|l|}{ Regurgitation grade } \\
\hline Median (IQR) & $0(0-0)$ & $1(0-1)$ & .102 \\
\hline Range & $0-1$ & $0-2$ & \\
\hline \multicolumn{4}{|l|}{ RVOT position $(\mathrm{n}=2)$} \\
\hline \multicolumn{4}{|l|}{ Gradient, mm Hg } \\
\hline Median (range) & $28(20-35)$ & $23(15-30)$ & .157 \\
\hline \multicolumn{4}{|l|}{ Regurgitation grade } \\
\hline Median (range) & $0(0-0)$ & $2(0-3)$ & .317 \\
\hline \multicolumn{4}{|l|}{ Balloon dilation \#3 } \\
\hline \multicolumn{4}{|l|}{ Mitral position $(\mathrm{n}=3)$} \\
\hline \multicolumn{4}{|l|}{ Gradient, mm Hg } \\
\hline Median (range) & $13(6-16)$ & $5(3-8)$ & .10 \\
\hline \multicolumn{4}{|l|}{ Regurgitation grade } \\
\hline Median (range) & $0(0-2)$ & $1(1-1)$ & .56 \\
\hline
\end{tabular}

$I Q R$, Interquartile range; $R V O T$, right ventricular outflow tract. $* P$ value significant $(<.05)$ before compared with after balloon dilation.

There are theoretical concerns regarding the durability of a venous valve within the systemic circulation. Similar to this study, previous studies have demonstrated the durability of the transcatheter Melody valve when subjected to systemic pressures. ${ }^{6-8}$ Endocarditis has been reported after transcatheter Melody valve implantation, and antibiotic prophylaxis before surgical or dental procedures is recommended. ${ }^{9}$

Mortality in this series (14\%) was related predominantly to patient selection. In the 3 patients experiencing hospital mortality, replacement was performed to salvage a moribund circulation in the setting of mechanical circulatory support and severely depressed ventricular function. In these patients, adequate valvular function was demonstrated before mortality, and autopsy did not reveal any evidence of valvular thrombosis or deterioration.

The patients with late mortality exhibited various combinations of ventricular noncompliance, arrhythmias, systolic dysfunction, and pulmonary hypertension before valve replacement that persisted even after replacement. High mortality after valve replacement in this subgroup of patients has been described previously. ${ }^{10}$ Earlier intervention in these patients might have mitigated the severity of dysfunction and improved survival. Given the current prosthetic options, many clinicians elect to medically manage a patient with significant valvular disease, referring them to surgery only after progressive clinical deterioration occurs. The availability of a durable expandable valve may allow clinicians to intervene earlier in the clinical course, before the development of irreversible injury.

Several patients experienced valve-related reoperations and SVD; however, in most of these patients, the complications were attributable to implantation techniques or design modifications. The Melody valve was designed for transcatheter use in the RVOT position, and thus surgical implantation tecniques had to be developed over the course of the study period. Mechanisms of SVD included penetration of the suture through the graft wall at the time of attachment of the pericardial skirt, with inadvertent injury to the underlying leaflet, and injury related to excessive stent resection. Adventitial removal during manufacturing results in an extremely thin conduit wall that is predisposed to this complication, as described previously. ${ }^{11}$ Two patients developed perivalvular leak related to dehiscence of the skirt. Subsequently, the technique for skirt attachment was modified to use 15 to 20 interrupted sutures that encircle only the stent material.

In 2 patients, the valve was implanted within a circumferential tube, without circumferential proximal and distal anastomoses. In both of these patients, significant perivalvular leak developed soon after the procedure, necessitating reoperation for re-replacement with a traditional fixeddiameter bioprosthetic valve. This implantation technique was subsequently abandoned.

In 1 patient, central regurgitation was related not to technical complications, but rather to improper patient selection. In this patient, the valve was implanted into a circulation without significant forward flow (Glenn circulation and patent ASD). In this scenario, prosthetic valves do not function appropriately because of insufficient opening and closing forces on the valve. Exclusion of such patients is reasonable considering the poor durability in this situation. 
In 1 patient, LVOTO occurring after mitral valve replacement necessitated reoperation. Here deviation of the distal stent into the left ventricular outflow tract predisposed this patient to obstruction. Because the Melody valve is long $(2.3-2.5 \mathrm{~cm})$, fixation at the midsection alone predisposes it to "tilt" toward the left ventricular outflow tract from ventricular flow patterns. Subsequent to this observation, fixation of the distal stent to the posterior left ventricular free wall has been instituted to prevent LVOTO. Development of LVOTO in a patient with congenital mitral stenosis also may be attributable to the natural progression of Shone's complex. ${ }^{12}$ Nevertheless, optimization of the valve design is likely to reduce the risk of LVOTO.

Commercial-grade design modifications may prevent many of the SVD complications encountered. The design requirements depend on the position in which the valve is implanted. For all positions, the shortest possible valve with a commercially designed sewing cuff is desired. For mitral, tricuspid, and aortic positions, scalloped sinuses (adjacent to the outflow tract or coronary sinuses) would prevent the need for modifications performed by the surgeon. Minor modifications to the valve design may significantly reduce or even eliminate many of the complications encountered in this series without affecting the performance and expandability of the valve itself. Attachment of the skirt at the time of valve manufacturing would eliminate the need for manual modification, thereby reducing operative times and also decreasing the risk of inadvertent leaflet injury and skirt dehiscence.

The median interval between catheter-based dilations was approximately 10 months, but this might be increased by more aggressive dilation. Early in our experience, aggressive dilation was not pursued owing to concerns about valve injury. Increases in valve internal diameter by as much as $4 \mathrm{~mm}$ were tolerated without the development of regurgitation. Further investigation is needed to determine whether the device retains expandability over the long term after multiple dilations.

In conclusion, the externally stented bovine jugular vein graft can be used as an expandable cardiac valve in pediatric applications. Enlargement of the valve with patient growth results in acceptable short-term function. Reoperation and perivalvular complications may be prevented by further refinements in valve design and implantation techniques. This technology may allow for a delay in reoperation in appropriately selected patients.

\section{Study Limitations}

Our patient cohort was heterogeneous, and thus the outcomes-particularly mortality- cannot be generalized from this study. Similarly, additional procedures performed at the time of valve replacement would certainly affect mortality.

\section{Webcast}

You can watch a Webcast of this AATS meeting presentation by going to: http://webcast.aats.org/2016/Video/ Tuesday/05-17-16_Ballroom_III_1420_Emani-800.mp4.

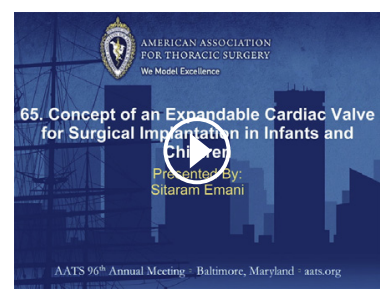

\section{Conflict of Interest Statement}

Authors have nothing to disclose with regard to commercial support.

\section{References}

1. Kaza AK, Lim HG, Dibardino DJ, Bautista-Hernandez V, Robinson J, Allan C, et al. Long-term results of right ventricular outflow tract reconstruction in neonatal cardiac surgery: options and outcomes. J Thorac Cardiovasc Surg. 2009;138:911-6.

2. Poynter JA, Eghtesady P, McCrindle BW, Walters HL III, Kirshbom PM, Blackstone EH, et al. Association of pulmonary conduit type and size with durability in infants and young children. Ann Thorac Surg. 2013;96:1695-701; discussion 701-2.

3. Abdullah I, Ramirez FB, McElhinney DB, Lock JE, del Nido PJ, Emani S. Modification of a stented bovine jugular vein conduit (melody valve) for surgical mitral valve replacement. Ann Thorac Surg. 2012;94:e97-8.

4. Quiñonez LG, Breitbart R, Tworetsky W, Lock JE, Marshall AC, Emani SM. Stented bovine jugular vein graft (Melody valve) for surgical mitral valve replacement in infants and children. J Thorac Cardiovasc Surg. 2014;148:1443-9.

5. Emani SM. Melody valve for mitral valve replacement. Oper Tech Thorac Cardiovasc Surg. 2014;19:454-63.

6. Hasan BS, McElhinney DB, Brown DW, Cheatham JP, Vincent JA, Hellenbrand WE, et al. Short-term performance of the transcatheter Melody valve in high-pressure hemodynamic environments in the pulmonary and systemic circulations. Circ Cardiovasc Interv. 2011;4:615-20.

7. McElhinney DB, Hellenbrand WE, Zahn EM, Jones TK, Cheatham JP, Lock JE, et al. Short- and medium-term outcomes after transcatheter pulmonary valve placement in the expanded multicenter US melody valve trial. Circulation. 2010;122:507-16.

8. Brizard CP, d'Udekem Y, Eastaugh LJ, Lane GK, Jones BO. Intra-annular mitral valve replacement in neonates and infants. J Thorac Cardiovasc Surg. 2015;149: 390-2.e1.

9. McElhinney DB, Benson LN, Eicken A, Kreutzer J, Padera RF, Zahn EM. Infective endocarditis after transcatheter pulmonary valve replacement using the Melody valve: combined results of 3 prospective North American and European studies. Circ Cardiovasc Interv. 2013;6:292-300.

10. Selamet Tierney ES, Pigula FA, Berul CI, Lock JE, del Nido PJ, McElhinney DB Mitral valve replacement in infants and children 5 years of age or younger: evolution in practice and outcome over three decades with a focus on supra-annular prosthesis implantation. J Thorac Cardiovasc Surg. 2008;136:954-61, e1-3.

11. Hofmann M, Dave H, Hübler M, Kretschmar O. Simplified surgical-hybrid Melody valve implantation for paediatric mitral valve disease. Eur J Cardiothorac Surg. 2015;47:926-8.

12. Delmo Walter EM, Komoda T, Siniawski H, Miera O, Van Praagh R, Hetzer R. Long-term surgical outcome of mitral valve repair in infants and children with Shone's anomaly. Eur J Cardiothorac Surg. 2013;43:473-81; discussion 81-2. 
Key Words: pediatric valve replacement, expandable valve, Melody valve, bovine jugular vein graft

\section{Discussion}

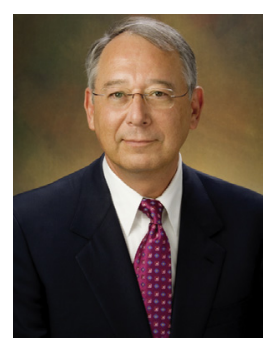

Dr Spray (Philadelphia, Pa). This is obviously an excellent large series of use of the Melody valve as off-label use for valve replacement in children. Some of these comments will relate to the manuscript. I think this would actually be a better study in some ways if you focused only on $\mathrm{AV}$ valve replacement.

When you look at these valve gradients and the median decrease in valve gradient with redilation, adding RV outflow tract gradients and aortic gradients I think skews the data. The mean gradient reduction in the mitral position is only a couple of millimeters of mercury. So that's a much more important feature I think, and maybe it would be advantageous to separate this out in the manuscript.

Also, more technical detail would be valuable, especially the details of balloon sizing in the AV position. What was the mean balloon diameter in the AV valve position that you used? I know that you try to use a balloon diameter that's similar to the appropriate $z$ value for the size of the child, but what was the actual mean balloon dilation diameter for the implantation initially and then at reimplantation? That would be very valuable information to know, and it isn't included in the manuscript. Do you happen to have that information, for example, in the $\mathrm{AV}$ valve position?

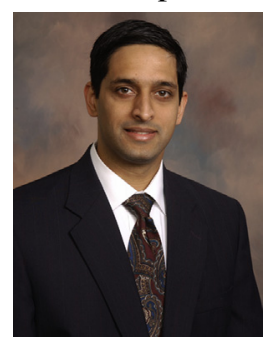

Dr Emani (Boston, Mass). We do not try to dilate the valve to a normal $z$ score for that patient, since most of these patients have annuli that are much below that. Typically, we use the echocardiogram to help with the sizing of the valve. If we have a child with a valve annulus of $12 \mathrm{~mm}$, we would only expand it to $13 \mathrm{~mm}$ even if the normal annular size is larger.

In this series, the median size of valve balloon expansion for all positions was 14. For the mitral, it was closer to 12 .

Dr Spray. Obviously there is some concern about excessive dilation, especially in the $\mathrm{AV}$ position, with concerns for creation of complete heart block or consideration of compromise of the circumflex coronary artery.

So how is this avoided? Obviously the amount of dilation at redilation is relatively modest and is that because of concerns about these problems, and how do you monitor that during the balloon redilation?

Dr Emani. At the time of implantation, we start by reviewing echo measurements. Once the valve is removed, we typically use a dilator to confirm the diameter of the annulus. There is a delicate balance; if you don't dilate the valve adequately, you end up with paravalvular leaks, because this is a relatively thin valve without a significant cuff on it. The cuff that we insert isn't very bulky. On the other hand, if you overdilate, you could end up with the complications of coronary artery injury or heart block.

What we have found is that if you use the echocardiogram for sizing and add to that number $1 \mathrm{~mm}$, this seems to be the appropriate balloon size.

Dr Spray. I noticed that pericardial skirt dehiscence is a problem. Does the skirt affect the size of the valve that you implant? And why do you feel the need for the skirt in the first place?

Dr Emani. The valve is quite long, and to facilitate implantation, you need a skirt. Otherwise, when you collapse the valve, it becomes impossible to actually place the sutures. Having a skirt there allows you to anchor your sutures to the annulus, and the skirt also acts as a sealant. The stent material up against the annulus I think can predispose to paravalvular leaks, and having a cuff of tissue there may facilitate the seal between the stent and the annulus, in the mitral position in particular.

Dr Spray. I noticed, if I read your manuscript correctly, that in the tricuspid position implants 2 out of 3 patients died, I think, but there was not a skirt on those valves. Why is it different in the tricuspid position?

Also, you don't anchor the valve in the tricuspid position either. Can you just talk about the technical issues of that?

Dr Emani. Yes, left ventricular outflow tract obstruction in the mitral position is of concern. Early in the experience, that was seemingly related to tilting of the valve toward the left ventricular outflow tract. Since it's a long valve, if it's only secured in the central portion, it can tilt toward the outflow tract during systole. So we have started placing a suture distally between the stent and the ventricle to prevent that from occurring.

In the tricuspid position, the pulmonary valve is further away from the inflow of the right ventricle, and so we haven't seen that same problem.

With regard to the skirt, early in our experience we did not use a skirt on patients, and some of these patients developed paravalvular regurgitation. For the aortic, mitral, and tricuspid, positions we're universally now using a skirt and have found that to improve the incidence of paravalvular leak.

Dr Spray. And, finally, you imply (and I agree) that it would be very valuable to have some modifications of the Melody design that would allow better and more accurate 
implantation. Do you think there is any realistic chance that this will become possible in the near future?

Dr Emani. There are ongoing discussions with the company, and I think they are interested in standardizing this. Obviously a redesign would require a new application to the FDA, and I think that's quite expensive. Hopefully we can muster resources.

We're trying to gather a multi-institutional experience with this valve, and we're hoping that together we could approach the company and the FDA.

Dr Spray. Thank you.

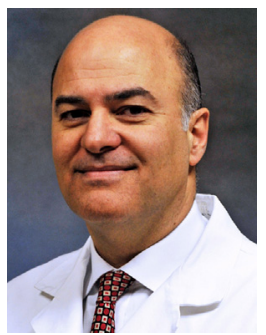

Dr Bacha (New York, NY). Ram, thank you for your leadership in this field. We followed your lead and, as you know, have implanted a number of these patients. We've tried it with other stented percutaneous valves and found that this didn't work as well as the Melody, so we're back to using the Melody.

A quick technical question. You talk about trimming the stent. We have been folding the stent over itself at each end as much as possible, and we've been actually quite happy with this. Is that something you do as well?

Dr Emani. I have not done that for the distal portion.

Dr Bacha. In the mitral position.

Dr Emani. Yes, in the mitral position. For the distal portion, unfortunately, to prevent LVOTO, you actually need to get rid of graft material in that position, and I found that folding the stent crowns back hasn't given me the distance that I need. But I think that's a reasonable option for the proximal part of the valve where you're looking to shorten it on that end.
Dr Bacha. It has worked well for us on both ends. Are you still using the stitch at the distal end to anchor the Melody down into the depth of the LV cavity?

Dr Emani. I am. The last one of the patients I did a few patients ago, actually the suture had come undone, and the patient developed LVOTO, so that reminded me of the importance of this.

Dr Bacha. And the final question. The difficult patients in whom this is really needed include, let's say, a $3-\mathrm{kg}$ baby with mitral valve dysplasia and a small left side with an obvious risk of LVOTO. I noticed that the youngest patient in your series was a 3 -week old.

What would you do now that you have accumulated the experience with this, how small would you go in terms of patient size?

Dr Emani. I look at the size of the ventricle, and I would base it upon that. I think our preference, as is yours, is to repair the valve as much as possible, and I think in some situations if you have an adequate right ventricle, it's not a wrong idea to go to a single-ventricle palliation for a period of time and then come back at four months to do something with the valve.

Dr Bacha. One quick question. Have you had patients with mechanical mitral valves in which you've decided to explant the valve to avoid coumadin and put a Melody in 3- or 5-year-old patients? Have you done that?

Dr Emani. We actually had a neonate who had a supraannular mechanical valve placed that thrombosed. We took it out, and put in a bioprosthetic valve. We later took that out and put in a Melody, and the child is currently home. 